\title{
Investigation on Preoperative Interview of Standardized Training for Anesthesiologists
}

\author{
Yifan Xue ${ }^{1,2}$, Rui Xia ${ }^{*}$, Dan Qiao ${ }^{1,2}$ \\ ${ }^{1}$ Department of Anesthesiology, The First Affiliated Hospital of Yangtze University, Jingzhou 434000, Hubei, China \\ ${ }^{2}$ Department of Anesthesiology, NO.2 Hospital of Baoding, Baoding 071000, Hebei, China \\ Email: 879560350@qq.com
}

\begin{abstract}
Objective - To investigate the current situation of preoperative interview of standardized training anesthesiologists in Hebei province by online questionnaire. To understand the current situation of preoperative interview of standardized training anesthesiologists and screen out the main factors affecting the preoperative interview of standardized training anesthesiologists. Method - The questionnaire is designed by the authors and is distributed through Wechat Mini Program. Questionnaire survey was conducted among standardized training anesthesiologists in several training bases in Hebei Province. Results - 313 valid questionnaires were collected. The standardized training anesthesiologists had problems such as lack of basic knowledge, lack of teacher's evaluation on their preoperative interview, and don't know how to improve. In addition, the number of preoperative interviews in neurosurgery and cardiothoracic surgery was relatively small, and the ability of preoperative interviews in specialized surgery was insufficient. Conclusion: To improve the quality of preoperative interviews, standardized training anesthesiologists need to improve the training and evaluation system and enhance teaching. Keywords: anesthesiologist, standardized residents training in hospital, preoperative interview
\end{abstract}

Preoperative interview includes effective communication with patients to relieve their psychological pressure. Conduct a detailed and comprehensive examination to fully assess the risks of surgery and anesthesia. Comprehensive analysis was made of the medical history, physical examination and laboratory results combined with the specific conditions of the operation, and anesthesia plans were made in accordance with the patient's situation ${ }^{[1-2]}$. Preoperative interviews are essential clinical skills for anesthesiologists. It is also one of the most basic skills that anesthesiologists must master during the learning stage.

Studies have shown that current anesthesiology residents have problems in preoperative interviews, such as incomplete medical history collection, less attention to surgical methods and scope, and poor ability to assess and explain risks related to surgery and anesthesia ${ }^{[3]}$. Because of this, improper preoperative examination, improper judgment, inadequate preparation and other situations still exist, temporary cancellation or postponement of surgery happened occasionally, even resulting in doctor-patient conflict ${ }^{[4]}$. In order to explore the current situation of preoperative interviews for standardized training of anesthesiology residents, we conducted a questionnaire survey on preoperative interviews for anesthesiology residents.

\section{Methods}

\subsection{The general information}

We conducted a questionnaire survey in anesthesiology departments of anesthesia training bases in Hebei Province from January 1, 2021 to February 28, 2021. A total of 326 questionnaires were received, of which 313 were valid, with a valid recovery rate of $96.01 \%$.

\subsection{Investigation method}

By interviewing managers, teachers and residents of the standardized residents training in hospital, summarizing common questions, referring to relevant literature, and combining the interview results, the questionnaire was designed by using the mini program "Questionnaire Star" in wechat.Age, education background, degree of mastery, self-evaluation, factors affecting Preoperative interviews and other multiple-choice questions were set in the table. All interviewees fill in the form anonymously.

\subsection{Statistical method}

Excel software was used for real-time statistical input of data, SPSS 22 statistical software was used for analysis, and the counting data were expressed as rate and composition ratio. 


\section{Results}

\subsection{The general information}

There were 99 (31.63\%) male residents and $214(68.37 \%)$ female residents in the survey population. The mean age was (26.7 \pm 2.38$)$ years. There are $152(48.24 \%)$ with bachelor's degree, 160 (51.44\%) with master's degree, and 1 with doctor's degree or above. Due to the small number of people with doctor's degree or above, this educational level will be dropped. In terms of years of training, $92(29.39 \%)$ residents in the first year, $85(27.16 \%)$ residents in the second year, $85(27.16 \%)$ residents in the third year and $51(16.29 \%)$ residents have completed the training.

\subsection{Analysis of preoperative interview}

$1.6 \%$ (5cases) residents thought that the surgeon was not able to cooperate with the anesthesiologist during the preanesthesiologist visit, thought that the anesthesiologist was too rigid, and hoped to perform the operation as soon as possible. $8.63 \%$ (27cases) residents thought the cooperation of surgeons was not good. In contrast, $31.95 \%$ (100cases) of the residents surveyed indicated that the surgeon was able to cooperate and improve the further examination, but they were often not satisfied with the evaluation results of the residents and expected the superior anesthesiologist to intervene and re-evaluate. $26.52 \%$ (83cases) of the residents thought that the surgeon was able to cooperate with the visit, but there was a slight gap in communication, and $31.31 \%$ (98cases) thought that the surgeon was able to cooperate well.

As for patients and their families, $15.02 \%$ (47cases) residents thought that patients and their families did not understand the importance of preoperative visits. While $17.25 \%$ (54cases) residents believed that patients and their family members could passively cooperate with the preoperative visit of anesthesia and understood the importance of preoperative visit. $38.02 \%$ (119cases) residents thought that patients and their family members could actively cooperate with preoperative anesthesia visit, and understood the importance of preoperative visit. 29.71\% (93cases) residents believed that patients and their family members could actively cooperate with the preoperative visit of anesthesia, and fully understood the importance of preoperative visit.

\subsection{Humanities survey of preoperative visits}

According to the questionnaire survey, preoperative anesthesia visit was approved by most of the residents, most of the residents fully understand the importance of preoperative anesthesia visit, can take the initiative to complete the preoperative visit and related work in accordance with the provisions. 57.19\% (179cases) of the residents attached great importance to preoperative visit and would make great efforts to do a good job in the visit of every patient. $37.38 \%$ (117cases) of residents approved preoperative visits and attached great importance to the visits of difficult cases, but they often paid little attention to the preoperative visits of ordinary patients. $5.11 \%$ (16cases) approved preoperative visits, but did not pay enough attention to them. Only 1 resident did not approve the preoperative visit.

For the influence of preoperative visit on anesthesia and surgical quality: $0.32 \%$ (1case )resident thought that preoperative visit could not improve anesthesia and surgical quality of patients; 7.03\% (22cases) residents thought that the effect of improving anesthesia and operation quality was not obvious; $19.81 \%$ (62 cases), 27.16\% (85 cases) and 45.69\% (143 cases) residents thought that preoperative visit had certain effect, obvious effect and significant effect in improving the quality of anesthesia and surgery, respectively.

\subsection{Comparison of different disciplines in preoperative visits}

First, the overall self-evaluation was conducted according to the standardized training anesthesiology residents' ability of preoperative visits. On the basis of the overall evaluation, the cases of residents of all ages and disciplines in preoperative visits were investigated, and then four grades of special self-evaluation were carried out for each discipline. The survey results are shown in Table 1-Table 3.

Table 1. Self-evaluation of each discipline $(\mathrm{N}-(\%))$

\begin{tabular}{|c|c|c|c|c|c|c|}
\hline & $\begin{array}{l}\text { overall } \\
\text { evaluation }\end{array}$ & $\begin{array}{l}\text { cardiothoracic } \\
\text { surgery }\end{array}$ & neurosurgery & obstetrics & $\begin{array}{l}\text { general } \\
\text { surgery }\end{array}$ & Total \\
\hline $\begin{array}{l}\text { (excellent)I can finish the preoperative } \\
\text { interview independently excellently }\end{array}$ & $53(16.93 \%)$ & $30(9.58 \%)$ & $36(11.5 \%)$ & $68(21.73 \%)$ & $90(28.75 \%)$ & $277(17.70 \%)$ \\
\hline $\begin{array}{l}\text { (good)I can complete the preoperative } \\
\text { interviews independently }\end{array}$ & $171(54.63 \%)$ & $117(37.38 \%)$ & $136(43.35 \%)$ & $171(54.63 \%)$ & $160(51.12 \%)$ & $755(48.24 \%)$ \\
\hline $\begin{array}{l}\text { (normal)I still lack the ability to visit } \\
\text { patients before anesthesia }\end{array}$ & $82(26.2 \%)$ & $122(38.98 \%)$ & $113(36.1 \%)$ & $64(20.45 \%)$ & $58(18.53 \%)$ & $439(28.05 \%)$ \\
\hline $\begin{array}{l}\text { (bad)I don't have the confidence to do it } \\
\text { alone }\end{array}$ & $7(2.24 \%)$ & $44(14.06 \%)$ & $28(8.9 \%)$ & $10(3.19 \%)$ & $5(1.6 \%)$ & $94(6.01 \%)$ \\
\hline
\end{tabular}


Table 2. Number of preoperative interviews in each discipline $(\mathrm{N})$

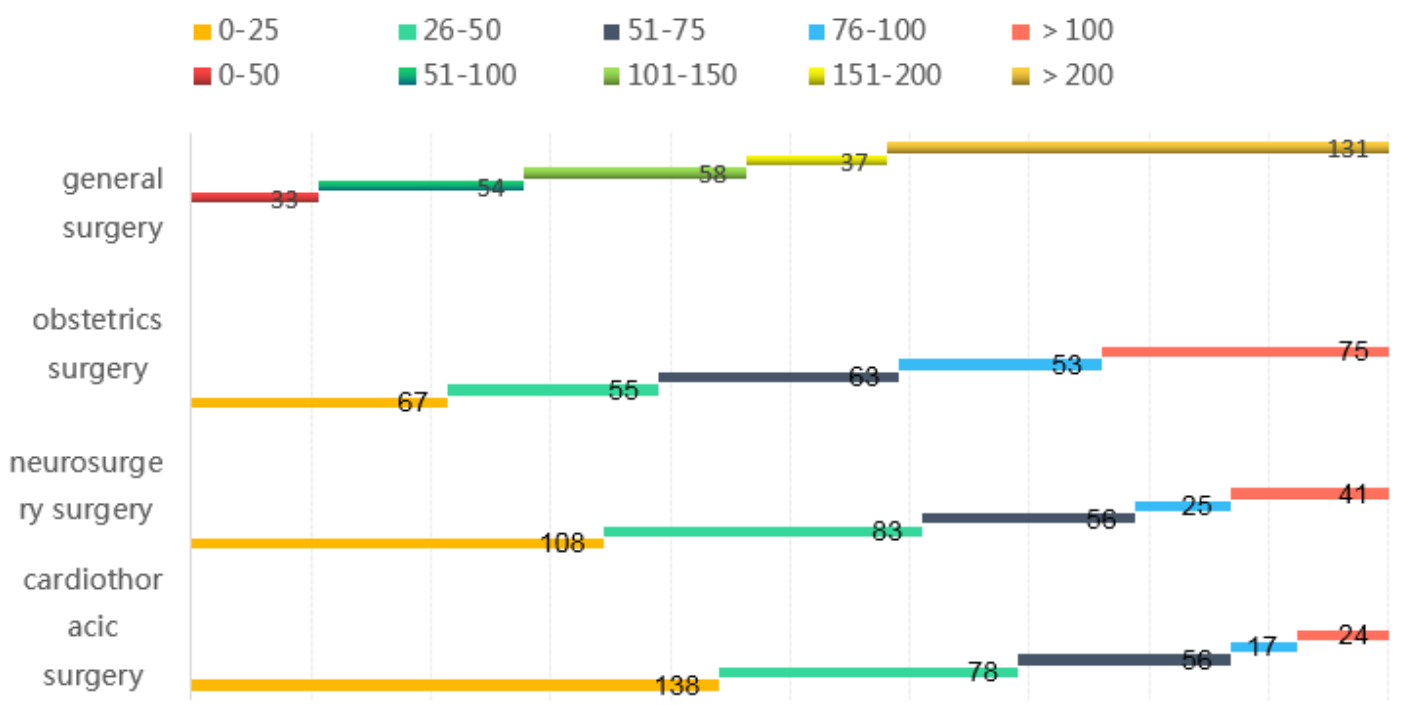

Table 3. Number of preoperative interviews by age group $(\mathrm{N}-(\%))$

\begin{tabular}{ccccccccc}
\hline Age/number of people & $0-25$ & $26-50$ & $51-75$ & $76-100$ & $101-125$ & $126-150$ & $151-200$ & $>200$ \\
\hline $0-18$ yers & $118(37.7 \%)$ & $60(19.17 \%)$ & $50(15.97 \%)$ & $46(14.7 \%)$ & $16(5.11 \%)$ & $9(2.88 \%)$ & $6(1.92 \%)$ & $8(2.56 \%)$ \\
$18-45 y e r s$ & $29(9.27 \%)$ & $44(14.06 \%)$ & $50(15.97 \%)$ & $43(13.74 \%)$ & $55(17.57 \%)$ & $30(9.58 \%)$ & $21(6.71 \%)$ & $41(13.1 \%)$ \\
$45-69 y e r s$ & $19(6.07 \%)$ & $31(9.9 \%)$ & $30(9.58 \%)$ & $49(15.65 \%)$ & $33(10.54 \%)$ & $41(13.1 \%)$ & $44(14.06 \%)$ & $66(21.09 \%)$ \\
$\geq 7$ yers & $36(11.5 \%)$ & $52(16.61 \%)$ & $42(13.42 \%)$ & $47(15.02 \%)$ & $28(8.95 \%)$ & $40(12.78 \%)$ & $33(10.54 \%)$ & $35(11.18 \%)$ \\
total & $202(16.13 \%)$ & $187(14.94 \%)$ & $172(13.74 \%)$ & $185(14.78 \%)$ & $132(10.54 \%)$ & $120(9.58 \%)$ & $104(8.31 \%)$ & $150(11.98 \%)$ \\
\hline
\end{tabular}

\subsection{Influencing factors of preoperative interview}

There are many factors that affect Preoperative interviews. Based on the preliminary investigation, nine common factors were screened in advance. Residents who accepted the questionnaire survey made multiple choices based on their actual situation, as shown in Table 4.

Table 4. Influencing factors of preoperative interview

\begin{tabular}{|c|c|c|}
\hline options & $\mathrm{n}$ & ratio \\
\hline $\begin{array}{l}\text { Preoperative interview is a relatively basic project, which lacks systematic teaching during the training } \\
\text { period, and is relatively neglected by schools or hospitals }\end{array}$ & 98 & $31.31 \%$ \\
\hline Lack of practice in visiting patients with complex conditions and opportunities for individual assessment & 97 & $30.99 \%$ \\
\hline $\begin{array}{l}\text { When the Preoperative interview is completed, there is a lack of senior doctors to evaluate the quality of their } \\
\text { visit, and they do not know how to improve it }\end{array}$ & 159 & $50.8 \%$ \\
\hline $\begin{array}{l}\text { When performing specialized surgeries, the basic knowledge and relevant theoretical knowledge are } \\
\text { insufficient, and some specialized surgeries cannot be reasonably evaluated }\end{array}$ & 178 & $56.87 \%$ \\
\hline $\begin{array}{l}\text { Due to the working pressure and the limitation of working hours, the visiting work will affect my rest and off } \\
\text { work, so the visiting work process will be relatively simplified }\end{array}$ & 134 & $42.81 \%$ \\
\hline After a lot of visiting work, the visiting work fatigue and gradually indifferent & 122 & $38.98 \%$ \\
\hline $\begin{array}{l}\text { Psychologically, Preoperative interview is not so important as anesthesia operation. As long as anesthesia is } \\
\text { done well in the operating room, Preoperative interview can also be ignored }\end{array}$ & 32 & $10.22 \%$ \\
\hline Dissatisfaction in other areas (such as salary or working conditions) that affect the quality of work & 55 & $17.57 \%$ \\
\hline $\begin{array}{l}\text { Preoperative interviews are often difficult due to poor cooperation between patients and their families, or } \\
\text { inability of surgeons to provide required patient information (such as imaging data) }\end{array}$ & 116 & $37.06 \%$ \\
\hline total & 313 & $100 \%$ \\
\hline
\end{tabular}




\section{Discussion}

Standardized training for residents is the only way for anesthesiology department to train residents to become qualified anesthesiologists with independent working ability ${ }^{[6]}$. To become a qualified anesthesiologist, the first contact is the preoperative interview. Adequate pre-anesthesia assessment and preparation can not only improve the safety of surgical anesthesia, accelerate the recovery of patients, but also significantly expand the scope and indications of surgery ${ }^{[7]}$. Good preoperative interviews can reduce the incidence of intraoperative complications and improve clinical outcomes.

A series of objective problems, such as "the time of anesthesiologist visit is not fixed", "the patient is not in the ward during the preoperative interview" and "the anesthesiologist does not attract enough attention", are still the reasons for the low success rate of the preoperative interview in the hospital ${ }^{[3]}$. However, it is more difficult for residents, who is inexperienced in anesthesia, to satisfy patients in preoperative interviews.According to a stratified sampling questionnaire survey, $73.3 \%$ of patients not only hope medical staff to know about their illness, but also hope medical staff to pay attention to their social relationship and social role, while the proportion of medical staff who "understand the illness" and "pay attention to patients" is only $26.7 \%$. ${ }^{[8]}$ The questionnaire sorted out the factors affecting the preoperative interview and found that"When performing specialized surgeries, the basic knowledge and relevant theoretical knowledge are insufficient, and some specialized surgeries cannot be reasonably evaluated"(56.87\%)". When the Preoperative interview is completed, there is a lack of senior doctors to evaluate the quality of their visit, and they do not know how to improve it "(50.80\%)". Due to the working pressure and the limitation of working hours, the visiting work will affect my rest and off work, so the visiting work process will be relatively simplified "(42.81\%) are the three main factors affecting the preoperative interview of residents. For residents, compared with other influencing factors, the most important is to improve the teaching of preoperative interviews. At present, in the teaching content of standardized anesthesiology residents training in China, there are requirements on the number of anesthesia in each subspecialty and various practical operations, but there are no relevant regulations on the number of cases of preoperative interviews. The director of the training base attach importance to preoperative interview determines the teaching quality of preoperative interview. To improve the preoperative visiting ability of anesthesiology residents, it is necessary to improve the appropriate training and teaching system of preoperative visiting based on the situation of each standardized training base and increase the opportunity of independent visiting, so as to better guarantee the perioperative anesthesia safety of patients.

In this survey, it was found that the number of preoperative interviews by standardized training anesthesiology residents in the 0-18 age group was relatively low, which may be related to the distribution of surgical patients in this age group. There were fewer pediatric patients and the patients were concentrated in pediatric hospitals. The situation of pediatric patients during anesthesia and surgery changes suddenly, the experienced superior doctors often lead the preoperative interview and other work, and the trained residents lack the opportunity to deal with the interview.Self-evaluation was concentrated in normal (38.98\% in cardiothoracic surgery, $36.1 \%$ in neurosurgery) and good (37.38\% in cardiothoracic surgery, $43.45 \%$ in neurosurgery), which was lower than that in general surgery and gynecology $(\mathrm{P}<0.05)$, which needs our attention. For children patients and patients with cardiothoracic surgery or neurosurgery, there are few cases, so teaching should be strengthened. Patients with typical characteristics can be standardized to reproduce the cases, and residents can be trained in history collection, clinical thinking, physical examination and other aspects.

Preoperative visiting is a basic skill that every anesthesiologist must master, and is one of the important indicators to test whether an anesthesiologist is qualified or not. Now there are many advanced teaching modes. For example, standardized patient (SP) scenario simulation, problem-based teaching method (PBL) combined with case-based learning (CBL) teaching mode in clinical teaching, evidence-based medicine combined with PBL teaching mode, and PDCA cycle mode ${ }^{[9-10]}$ can be used for reference in anesthesiology teaching. Vigorously improve the formal training of anesthesiologists ${ }^{[5]}$, to optimize our anesthesia process and improve the quality of anesthesia.

\section{References}

[1] Pre-Operative Assessment and Preparation. The role of the anaesthetist. AAGBI, 2010. http://www.aagbi.org/sites/ default/files/preoperativeass01.pdf. Accessed September 4, 2014.

[2] Cooray TC. Audit to evaluate the patients view, regarding the preoperative visit of the patients by the anaesthetist[J]. Sri Lankan Journal of Anaesthesiology, 2011, 19: 39-42.

[3] GONG Ya-hong, WANG Wei-jia, YU Chun-hua, et al. Status and training of preoperative anesthetist visit in anesthesia residents[J]. Basic \& Clinical Medicine, 2017, 37(8): 1202-1205.

[4] Deng Xiaoming, Yao Shanglong, Yu Buwei et al. Modern Anesthesiology (4th Ed.)[M]. People's Medical Publishing 
House, 2019, page 27.

[5] Deng Shuozeng, Song Haibo, Liu Jin. Safety is the eternal theme of anesthesia [J]. Journal of Clinical Anesthesiology, 2009, 25(4): 360.

[6] Li Yonghua, Jiang Xin, Fu Hailong et al. Investigation of Ultrasound-guided Artery and Central Venous Catheterization in Residents Standardization Training of Anesthesiology [J]. China Continuing Medical Education, 2019, 11(28): 4850.

[7] Deng Xiaoming, Yao Shanglong, Yu Buwei et al. Modern Anesthesiology (4th Ed.)[M]. People's Medical Publishing House, 2019, page 899.

[8] Ye Lineng, Liu Hong. Focus research on diagnosis and treatment based on patient-disease-medicine humanistic level[J]. Chinese Journal of Hospital Administration, 2017, 3(6): 423-425.

[9] Ni Qing, Yang Yanan. Methods of clinical teaching and management of professional departments of resident doctors[J]. Beijing Journal of Traditional Chinese Medicine, 2019, 38(01): 79-81+88.

[10] Le Xiao, GUO Yue, Zhao Tiyu. Research progress of preoperative visit model at home and abroad[J]. Journal of Nursing (China), 2015, 22(13): 13-17. 